УДК 541.127

\title{
ИЗУЧЕНИЕ АНТИОКСИДАНТНЫХ СВОЙСТВ ЛЕКАРСТВЕННЫХ РАСТЕНИЙ ГОРИССКОГО РЕГИОНА АРМЕНИИ
}

\author{
() Р.Л. Варданян", Л.Р. Варданян, Л.В. Атабекян, Т.С. Григорян \\ Горисский государственный университет, ул. Авангарда, 4, Горис, 3205 \\ (Армения), e-mail: vrazmik@rambler.ru
}

Исследовано антиоксидантное действие экстрактов из различных органов 11 лекарственных растений, произрастающих в Горисском регионе Армении. Установлено, что из исследованных экстрактов наибольшее количество антиоксидантов содержатся в плодах жостера и в траве фенхеля конского, а по антиоксидантной активности выделяется экстракт из цветков и корней шафрана.

Ключевые слова: лекарственные растения, антиоксиданты, экстракты, окисление, кумол.

\section{Введение}

Причинами проявления сердечно-сосудистых, желудочно-кишечных, злокачественных опухолей и других заболеваний является накопление в организме излишних концентраций свободных радикалов. Для урегулирования концентрации радикалов в живых организмах вырабатываются специальные вещества - различные ферменты, витамины, обладающие антиоксидантными свойствами. Эти соединения являются ловушкой для свободных радикалов. Естественно, что для профилактики вышеуказанных заболеваний рекомендуются лекарства с содержанием антиоксидантов растительного происхождения [1-3].

Набор антиоксидантов в растениях гораздо богаче, чем в тканях животных и человека. Это объясняется тем, что растения практически не имеют никаких других средств защиты от агрессивного воздействия окружающей среды. На сегодняшний день известно около 6000 антиоксидантов растительного происхождения [4, 5], объединенных под общим термином - флавоноиды. Все биофлавоноиды в своей основе имеют общую структуру $\mathrm{C}_{6}-\mathrm{C}_{3}-\mathrm{C}_{6}$, и благодаря наличию гидроксильных групп они являются ловушкой для свободных радикалов. Причем антиоксидантные свойства биофлавоноидов зависят от количества гидроксильных групп [6, 7].

Антиоксидантный состав каждого конкретного растения неповторим как в качественном, так и в количественном отношении. Каждое растение, обладая своей уникальной композицией биоантиоксидантов, одновременно зависит от времени вегетации, от географической местности и климатических условий произрастания [8-10]. Следовательно, прежде чем рекомендовать данное лекарственное растение как продукт, содержащий антиоксиданты, обязательным является изучение его антиоксидантных свойств с указанием географической местности и времени сбора растения.

Цель настоящей работы - изучение антиоксидантной активности и определение содержания антиоксидантных веществ в экстрактах листьев и плодах некоторых лекарственных растений, произрастающих

Варданян Размик Левонович - проректор, доктор химических наук, профессор, e-mail:vrazmik@rambler.ru

Варданян Луиза Размиковна - заведующая кафедрой общей химии, кандидат химических наук, доцент, e-mail:vrazmik@rambler.ru

Атабекян Лилит Валериковна - преподаватель Григорян Татевик Суреновна - преподаватель в Горисском регионе Армении. В Горисском регионе, с его уникальным географическим рельефом (от пустынных до альпийских), произрастают самые разные (более 1000 видов) лекарственные растения, и для практической цели важным является изучение этих растений как источников биоантиоксидантов.

\footnotetext{
*Автор, с которым следует вести переписку.
} 
Таблица 1. Целебные свойства исследованных растений

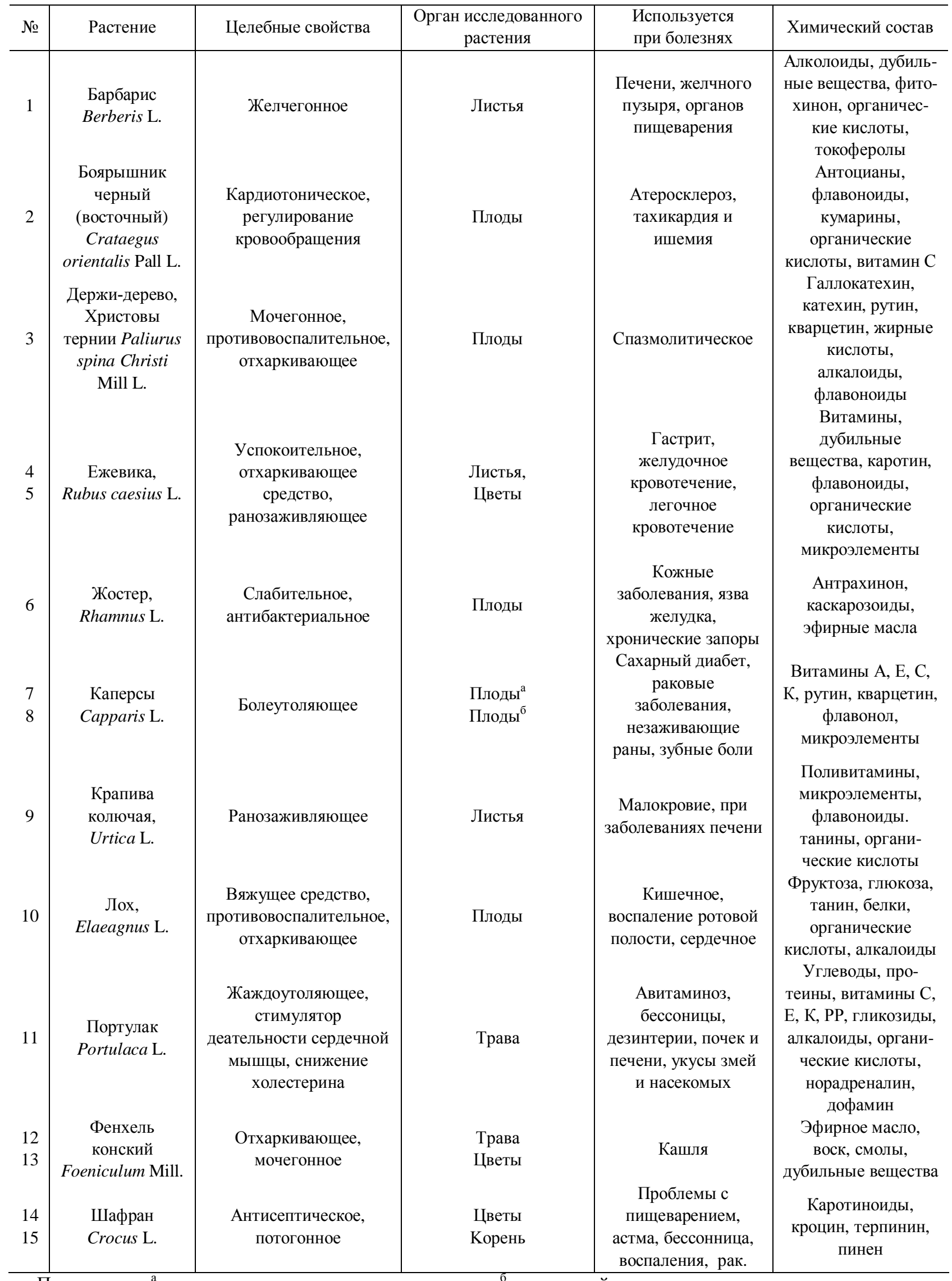

Примечания: ${ }^{\text {a }}$ экстракт получен прессованием плодов, ${ }^{6}$ этанольный экстракт. 


\section{Экспериментальная часть}

В качестве объекта исследования использованы приведенные в таблице 1 растения, где вкратце описано их применение в медицине для лечения той или иной заболеваемости [11]. Из химического состава (см. табл. 1) видно, что все исследованные растения содержат продукты, обладающие антиоксидантными свойствами (флавоноиды, токоферолы, катехины, каротиноиды и т.д.). Следовательно, экстракты из разных органов этих растений (листья, плоды, цветы) должны обладать существенными антиоксидантными свойствами. Экстракты получали следующим образом: после сбора объекты высушивали в сушильном шкафу при $40{ }^{\circ} \mathrm{C}$ до постоянной массы, далее растирали в керамической ступке до порошкообразного состояния, в полученный порошок при комнатной температуре добавляли дважды перегнанный бензол соотношением $1: 20$ (за исключением плодов каперсов), дали отстояться одни сутки, далее отфильтровывали бумажным фильтром. Фильтрат при комнатной температуре испаряли в вакуумном шкафу до постоянного веса.

Антиоксидантные свойства и их количественное содержание в полученных экстрактах определили на модельной реакции окисления кумола, инициированного азо-ди-изобутиронитрилом (АИБН). Опыты по окислению проводили на газометрической установке с автоматическим регулированием давления [12]. Использованные реактивы (кумол, хлорбензол, АИБН) очищали по методике, описанной в работе [13].

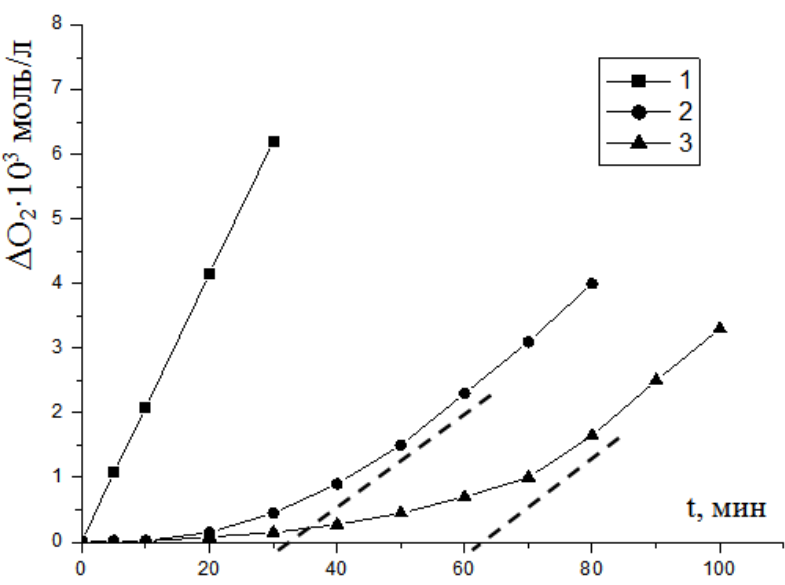

Рис. 1. Кинетические кривые поглощения кислорода кумолом в отсутствие (1) и в присутствии 1мг (2) и 2 мг (3) экстракта из плодов жостера: $\mathrm{V}_{\mathrm{i}}=1,63 \cdot 10^{-7}$ моль/л·с; $[\mathrm{RH}]=2,87$ моль/л; $\mathrm{T}=351 \mathrm{~K}$

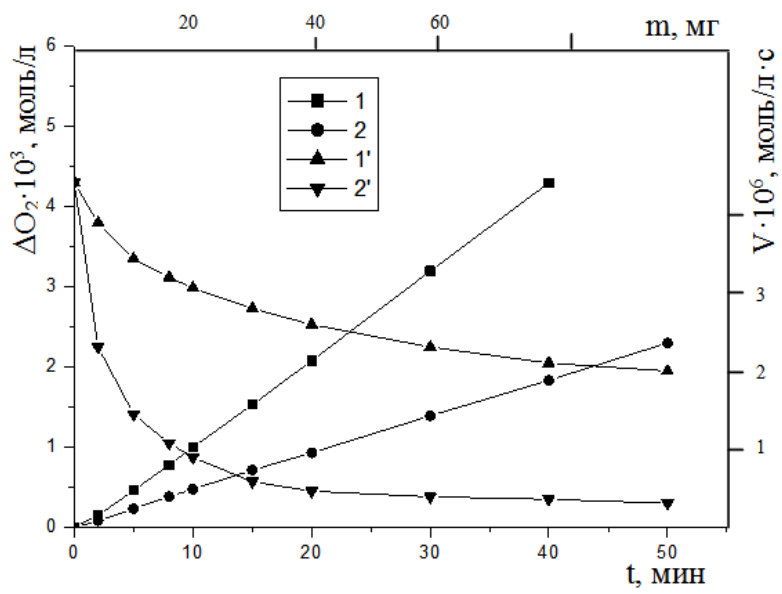

Рис. 2. Кинетические кривые поглощения кислорода кумолом в присутствие 120 мг ЭК (1) и 20 мг ЭДД (2) и зависимость параметра Ф от массы ЭК (1') и ЭДД (2'): $\mathrm{V}_{\mathrm{i}}=1,63 \cdot 10^{-7}$ моль/л сс; $[\mathrm{RH}]=2,87$ моль/л; Т=351К

\section{Обсуждение результатов}

Установлено, что при введении в систему АИБН - кумол - хлорбензол исследованных экстрактов (за исключением плодов из каперсов - ЭК и держи-дерево - ЭДД) на кинетических кривых поглощения кислорода появляются четко выраженные периоды индукции, что свидетельствует о наличии в них антиоксидантных веществ. Для иллюстрации на рисунке 1 представлены кинетические кривые поглощения кислорода кумолом в присутствии различных добавок экстрактов из плодов жостера. Обнаруженные периоды индукции описываются уравнением (1), что позволило определить эффективные содержания антиоксидантов (f[InH]) в исследованных экстрактах

$$
\tau=f \cdot[\operatorname{InH}] \cdot V_{i},
$$

где [InH] - концентрация антиоксидантов в использованном экстракте; $f$ - число радикалов, обрывающихся на одной молекуле антиоксиданта; $V_{\mathrm{i}}-$ скорость инициирования.

Помимо содержания антиоксидантов, за время периода индукции из кинетических кривых вычислен

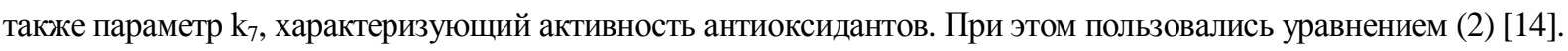

$$
\Delta O_{2} /[R H]=-\frac{k_{2}}{k_{7}} \ln \left(1-\frac{t}{\tau}\right),
$$

где $\Delta \mathrm{O}_{2}$ - концентрация поглощенного кислорода за время $t<\tau$; [RH] - концентрация кумола $(2,87$ моль/л); $\tau$ - период индукции; $k_{2}$ и $k_{7}$ - константы скоростей реакций продолжения: 


$$
R O_{2}^{\bullet}+R H \rightarrow R O O H+R^{\bullet}
$$

и линейного обрыва цепей:

$$
\mathrm{RO}_{2}^{\bullet}+\mathrm{InH} \rightarrow \mathrm{ROOH}+\mathrm{In}^{\bullet}
$$

При расчете $k_{7}$ учитывали, что для кумола $k_{2}=4,67710^{7} \exp (-6800 / \mathrm{RT})$ [15].

Из кинетических кривых поглощения кислорода (см. рис. 1) следует, что скорость окисления кумола после выхода из периодов индукции для всех исследованных экстрактов остается существенно заниженной по сравнению со скоростью окисления чистого кумола (на рисунке 1 сравните тангенсы углов прямых 1,2 и 3). Причем в случае экстрактов из плодов каперсов (экстракт получен методом прессования) и держидерева кинетика поглощения кислорода кумолом осуществляется без периодов индукции (рис. 2, прямые 1 и 2), оставаясь заниженной по сравнению со скоростью его безингибированного окисления. Во всех случаях обнаруженные предельные скорости окисления кумола (V) в присутствии исследованных экстрактов и скорость окисления чистого кумола $\left(\mathrm{V}_{0}\right)$ находятся в соотношении (3) [14].

$$
\Phi=\frac{V_{0}}{V}-\frac{V}{V_{0}}=\frac{f k_{71}[Q]}{\sqrt{k_{6} V_{i}}},
$$

где [Q] - концентрация продуктов окисления антиоксидантов в экстрактах. Предлагается, что $Q$ образуется по реакции:

$$
R \mathrm{O}_{2}^{\bullet}+\mathrm{In}^{\bullet} \rightarrow Q+\text { молекулярные продуктьі }
$$

где $k_{71}$ и $k_{6}-$ константы скоростей реакции линейного

$$
\mathrm{RO}_{2}^{\bullet}+Q \rightarrow Q^{\bullet}+\mathrm{ROOH}^{\bullet}
$$

и квадратичного обрыва цепей

$$
\mathrm{RO}_{2}^{\bullet}+\mathrm{RO}_{2}^{\bullet} \rightarrow \text { молекулярные продукты }{ }^{\bullet} .
$$

Спрямляя экспериментальные данные в координатах уровнения (3), для всех исследованных экстрактов вычислили параметры антиоксидантной активности $\left(k_{71}\right)$. При расчетах учитывали, что для кумола $k_{6}=4,74 \cdot 10^{5} \cdot \exp (-1800 / \mathrm{RT})[15]$.

\begin{tabular}{|c|c|c|c|c|c|}
\hline $\begin{array}{c}\text { Объект } \\
\text { исследования }\end{array}$ & $\begin{array}{l}\text { Время сбора } \\
\text { сырья }\end{array}$ & $\begin{array}{c}\text { Место произрастания растения } \\
\text { / высота от уровня моря, м }\end{array}$ & $\begin{array}{c}f[\operatorname{InH}] \cdot 10^{4}, \\
\text { моль/л }\end{array}$ & $\begin{array}{c}k_{7} \cdot 10^{-4}, \\
\text { л/моль } \cdot{ }^{\text {а }}\end{array}$ & $\begin{array}{c}k_{71} \cdot 10^{-2}, \\
\text { л/моль } \text { c }^{\text {а }}\end{array}$ \\
\hline 1 & 25.04 & с. Галидзор / 1100 & 0,83 & 2,93 & 8,26 \\
\hline 2 & 30.09 & г. Горис / 1500 & 0,67 & 2,41 & 6,46 \\
\hline 3 & 20.10 & Воротанское ущелье / 1200 & $-{ }^{\sigma}$ & $-{ }^{\sigma}$ & $0,014^{\mathrm{B}}$ \\
\hline 4 & 29.06 & г. Горис /1470 & 0,65 & 1,33 & 2,81 \\
\hline 5 & 29.06 & г. Горис / 1470 & 0,53 & 5,28 & 3,61 \\
\hline 6 & 15.10 & с. Татев / 1900 & 2,94 & 1,62 & 2,95 \\
\hline 7 & 15.08 & г. Ереван / 900 & $-{ }^{6}$ & -6 & $0,0012^{\mathrm{B}}$ \\
\hline 8 & 15.08 & г. Ереван / 900 & 0,11 & 2,08 & 7,40 \\
\hline 9 & 15.03 & г. Горис / 1470 & 0,35 & 2,50 & 1,28 \\
\hline 10 & 02.10 & г. Арташат / 700 & 0,27 & 1,85 & 7,68 \\
\hline 11 & 25.07 & г. Горис / 1400 & 1,45 & 0.55 & 10,23 \\
\hline 12 & 03.07 & г. Джермук / 2200 & 2,65 & 1,49 & 1,53 \\
\hline 13 & 03.07 & г. Джермук / 2200 & 1,00 & 1,55 & 1,49 \\
\hline 14 & 20.10 & с. Хндзореск / 1450 & 0,12 & 7,04 & 27,78 \\
\hline 15 & 20.10 & с. Хндзореск / 1450 & 0,17 & 7,02 & 20,48 \\
\hline
\end{tabular}

Результаты по измерению содержания антиоксидантов $(f \cdot[\mathrm{InH}])$, и их антиоксидантой активности (параметры $k_{7}$ и $k_{71}$ ) приведены в таблице 2 . Из таблицы 2 следует, что из исследованных экстрактов наибольшее количество антиоксидантов содержится в плодах жостера $\left(2,9 \cdot 10^{-4}\right.$ моль/л·мг), и в траве фенхеля конского $\left(2,65 \cdot 10^{-4}\right.$ моль/л·мг), а наиболее активным антиоксидантом является экстракт из цветов и корней шафрана.

Таблица 2. Содержание антиоксидантов в 1 мг экстракта и их активность, $T=351 \mathrm{~K}$

Примечания: ${ }^{\mathrm{a}}$ погрешность измеренных величин не превышала $10 \% ;{ }^{6}$ в присутствии этих экстрактов кинетика поглощения кислорода осуществляется без периодов индукции; ${ }^{\text {в }}$ размерность $\mathrm{k}_{71}(\mathrm{Mг} \cdot \mathrm{c})^{-1}$. 


\section{Заключение}

Исследовано антиоксидантное действие экстрактов различных органов лекарственных растений, произрастающих в Горисском регионе Армении. Экспериментально установлено, что все исследованные экстракты довольно долго проявляют антиоксидантные свойства и являются примерами отрицательного катализа в реакциях окисления. Измерено содержание антиоксидантных веществ в иследованных экстрактах и их антиоксидантные активности.

\section{Список литературы}

1. Kim H.P., Mani I., Ziboh V.A. Effects of naturally-occurring flavonoids and biflavonoids on epidermal cyclooxygenase from guinea pigs // Prostaglandins Leukot Essent Fatty Acids. 1998. Vol. 58. Pp. 17-24.

2. Marfak A., Trouillas P., Allais Redox reactions obtained by irradiation of quercetin methanol solution ar similar in vivo metabolism // Radiat Res. 2003. Vol. 159. Pp. 218-227.

3. Della Loggia R.,Tubaro A., Sosa S. The role of triterpenoids in the topical anti - inflammantory activity of Calendula officinalis flowers // Plante Medica. 1994. Vol. 60. Pp. 516-520.

4. Пепанян А.А. Использование антиоксидантов в косметологии // Вестник медицинского института им. Меграбяна. Ереван, 2007. С. 34-39.

5. Hanaski Y., Ogawa S., Fukui S. The correlation between oxygen scavenging and antioxidative effects of flavonoids // Free radic. Biol Med. 1994. Vol. 8. Pp. 77-97.

6. Денисов Е.Т., Денисова Т.Г. Реакционная способность природных фенолов // Успехи химии. 2009. Т. 78 , №11. C. $1129-1155$.

7. Tikhonov I., Roginsky V., Pliss E. The Chain - breaking antioxidant activity of phenolic compounds with different of $\mathrm{OH}$ groups as determinend during the oxidation of styrene // Int. J. Chem. Kinet. 2009. Vol. 41. Pp. 92-100.

8. Варданян Р.Л., Варданян Л.Р., Атабекян Л.В. Динамика накопления антиоксидантных веществ в листьях смородины черной // Сб. трудов Международной научной конференции Горисского государственного университета. Горис, 2010. С. 60-68.

9. Дмитриевна Г.Ю. Влияние экологических факторов на содержание в растениях некоторых антиоксидантов : автореф. дисс. ... канд. биол. наук. Калининград, 2009. 25 с.

10. Атабекян Л.В. Определение количественного содержания флавоноидов в листьях глухой крапивы (Яснотка Белая) - Laminum Album L. и барбариса - Berberus // Химический журнал Армении. 2012. T. 65, N1. С. 34-38.

11. Оганесян Дж.О. Зеленая аптека. Ереван, 2005. 328 с.

12. Эмануэль Н.М., Денисов Е.Т., Майзус 3.К. Цепные реакции окисления углеводородов в жидкой фазе. М., 1965. $375 \mathrm{c}$.

13. Варданян Л.Р. Кинетика инициированного персульфатом калия окисления эмульгаторов в водных растворах и их стабилизация : дис. ... канд. хим. наук. Ереван, 2004. 124 с.

14. Денисов Е.Т., Азатян В.В. Ингибирование цепных реакций. Черноголовка, 1997. 268 с.

15. Денисов Е.Т. Константы скорости жидкофазных гомолитических реакций. М., 1971. 712 с.

Поступило в редакичию 19 марта 2012 г.

После переработки 1 декабря 2012 г. 
Vardanian R.L. , Vardanian L.R., Atabekian L.V., Grigorian T.S. STUDY OF THE ANTIOXIDANT CHARACTERISTICS OF SOME MEDICINAL PLANTS OF GORIS REGION OF ARMENIA

The antioxidant influence of the extract from different organs of 11 medicinal plants growing in Goris region of Armenia has been studied.

It has been stated that from all the studied extracts that of the berries of Rhamnus L. and the grass of Foeniculum mill. have the highest content of antioxidants and the extract from the flowers and roots of Crocus L. has the highest antioxidant activity.

Keywords: medicinal plants, antioxidants, extracts, oxidation, cumene.

\section{References}

1. Kim H.P., Mani I., Ziboh V.A. Prostaglandins Leukot Essent Fatty Acids, 1998, vol. 58, pp. 17-24.

2. Marfak A., Trouillas P. Radiat Res., 2003, vol. 159, pp. 218-227.

3. Della Loggia R.,Tubaro A., Sosa S. Plante Medica., 1994, vol. 60, pp. 516-520.

4. Pepanian A.A. Vestnik meditsinskogo instituta im. Megrabiana. Erevan, 2007, pp. 34-39. (in Russ.).

5. Hanaski Y., Ogawa S., Fukui S. The correlation between oxygen scavenging and antioxidative effects of flavonoids // Free radic. Biol Med. 1994. Vol. 8. Pp. 77-97.

6. Denisov E.T., Denisova T.G. Uspekhi khimii, 2009, vol. 78, no. 11, pp. 1129-1155. (in Russ.).

7. Tikhonov I., Roginsky V., Pliss E. Int. J. Chem. Kinet., 2009, vol. 41, pp. 92-100.

8. Vardanian R.L., Vardanian L.R., Atabekian L.V. Sbornik trudov Mezhdunarodnoi nauchnoi konferentsii Gorisskogo gosudarstvennogo universiteta. [Proceedings of the International Conference of Goris State University]. Goris, 2010, pp. 60-68. (in Russ.).

9. Dmitrievna G.Iu. Vliianie ekologicheskikh faktorov na soderzhanie v rasteniiakh nekotorykh antioksidantov : avtoref. diss. ... kand. biol. nauk. [The influence of environmental factors on the content of some antioxidants in plants: the Dissertation of $\mathrm{PhD}$ ]. Kaliningrad, 2009. 25 p. (in Russ.).

10. Atabekian L.V. Khimicheskii zhurnal Armenii, 2012, vol. 65, no. 1, pp. 34-38. (in Russ.).

11. Oganesian Dzh.O. Zelenaia apteka. [Green Pharmacy]. Yerevan, 2005, 328 p. (in Russ.).

12. Emanuel' N.M., Denisov E.T., Maizus Z.K. Tsepnye reaktsii okisleniia uglevodorodov v zhidkoi faze. [Continued oxidation of hydrocarbons in the liquid phase]. Moscow, 1965, 375 p. (in Russ.).

13. Vardanian L.R. Kinetika initsiirovannogo persul'fatom kaliia okisleniia emul'gatorov $v$ vodnykh rastvorakh i ikh stabilizatsiia : dis. ... kand. khim. nauk. [Kinetics initiated by potassium persulfate oxidation of emulsifiers in aqueous solutions and their stabilization: The dissertation of the candidate Chem. Science]. Yerevan, 2004, 124 p. (in Russ.).

14. Denisov E.T., Azatian V.V. Ingibirovanie tsepnykh reaktsii. [Inhibition of chain reactions]. Chernogolovka, 1997,268 p. (in Russ.).

15. Denisov E.T. Konstanty skorosti zhidkofaznykh gomoliticheskikh reaktsii. [The rate constants of liquid-phase reactions of homolytic]. Moscow, 1971, 712 p. (in Russ.).

Received March 19, 2012

Revised December 1, 2012

\footnotetext{
"Corresponding author.
} 